\title{
Analysis on Marketing Segmentation of McDonald's
}

\author{
Jing An \\ UCSB College of Letter and Science, U.S \\ Jing_An@Ucsb.Edu
}

\begin{abstract}
McDonald's is one of the most popular fast-food restaurants companies in the world. The way McDonald's built its marketing segmentation remains mysterious. Though there are multiple articles online discussing its marketing strategy, none of them clearly indicate the different approaches McDonald's utilized to build its marketing segmentation. In order to analyze McDonald's approaches to build marketing segmentation, seven different countries' McDonald's websites are visited and the product types information from the official menu list on the websites are extracted. These seven countries represent seven continents while Antarctica is not considered. India and China are chosen since they are the most populated countries on the Earth. Then, every approach that McDonald's using in building marketing segmentation is listed out and how these approaches contribute to the overall structure is analyzed. The approaches all have advantages and drawbacks at the same time. Meanwhile, the five-year total return rates indicate that McDonald's has won its customers' hearts in these several years.
\end{abstract}

\section{CCS CONCEPTS}

-Applied computing; $\bullet$ Enterprise computing; $\bullet$ Business process management;

\section{KEYWORDS}

Fast food, marketing segmentation

\section{ACM Reference Format:}

Jing An. 2020. Analysis on Marketing Segmentation of McDonald's. In 2020 The 4th International Conference on E-Business and Internet (ICEBI 2020), October 09-11, 2020, Singapore, Singapore. ACM, New York, NY, USA, 4 pages. https://doi.org/10.1145/3436209.3436886

\section{INTRODUCTION}

McDonald's is one of the most popular restaurant chains in the world. Nowadays, there are more than 40000 McDonald's restaurants globally which serve tens of millions of customers every day [2]. The question becomes what did McDonald's do in order to make sure its customers stuck on McDonald's products. The difficult part is that each of the customers has a different profile. The profile could include elements as broad as nationality and elements that are much more specific such as preference of meat. To satisfy

Permission to make digital or hard copies of all or part of this work for personal or classroom use is granted without fee provided that copies are not made or distributed for profit or commercial advantage and that copies bear this notice and the full citation on the first page. Copyrights for components of this work owned by others than ACM must be honored. Abstracting with credit is permitted. To copy otherwise, or republish to post on servers or to redistribute to lists, requires prior specific permission and/or a fee. Request permissions from permissions@acm.org.

ICEBI 2020, October 09-11, 2020, Singapore, Singapore

(c) 2020 Association for Computing Machinery.

ACM ISBN 978-1-4503-8857-3/20/10 .\$15.00

https://doi.org/10.1145/3436209.3436886 all these needs, it's crucial to know about customers and build a marketing segmentation so that the other departments could start advertising and branding accordingly. Indeed, McDonald's marketing team does a lot of work behind and one of its jobs is to build customer segmentation in order to know their customers better and target new potential customers. In the following text, the goal is to explore what approaches do McDonald's use to build marketing segmentation.

\section{METHODOLOGY}

\subsection{Data Collection}

McDonald's is a giant international fast-food company. Aside from its operation in the U.S, McDonald's also operates in another 117 countries across the world [1]. In addition, these 118 countries in total cover all seven continents. Since the goal is to explore all approaches used by McDonald's to build its marketing segmentation and geographic approach is one of its components. It's necessary to pick countries that represent its continents. The menu information would be extracted from each country's McDonald's website. It's logically sound to select countries that have the most population in its continents. Thus, the following countries were selected which are the U.S, China, India, Brazil, Egypt, Australia and Germany. The reason that Egypt is chosen instead of the two other countries with more population is that those two countries do not have McDonald's operation as for now. Meanwhile, China and India are selected together because they are two of the most populated countries in the world and they have almost identical populations as now. Last but not least, Russia does not have an official McDonald's site which makes the data collection impossible. In this case, Russia was replaced with Germany which are on the second place with most population in Europe.

\subsection{Geographic Approach}

McDonald's is an international fast-food chain. In this case, it not only has restaurants in the U.S, but also in other countries. People living in different countries have very different eating habits and cultural backgrounds. Therefore, McDonald's must segment different regions correctly in order to keep its dominance in the globe. In Table 1, region and density are the two major criteria McDonald's take into account. Under the region criteria, it indicates whether the region is domestic or international is the first parameter McDonald's takes into account. McDonald's developed further strategies to perfect its marketing segmentation plan. In fact, McDonald's menus differ all over the world. As a result of different preferences on the meat kind, McDonald's adjusts its menu accordingly in different countries.

Table 2 displays the distribution of McDonald's flagship product(burgers) on the menu in different regions around the world. 
Table 1: Geographical approach to McDonald's marketing segmentation

\begin{tabular}{lll}
\hline Type of segmentation & Segmentation criteria & McDonald's target segment \\
\hline Geographic & Region & Domestic/international \\
& Density & Urban/rural \\
\hline
\end{tabular}

Table 2: of burgers in each country [4]

\begin{tabular}{llllll}
\hline Country & Chicken "burger" types & percentage & Beef "burger" types & Percentage & other(fish/veggie) \\
\hline U.S & 2 & $16.66 \%$ & 9 & $75 \%$ & 1 \\
China & 3 & $23.07 \%$ & 8 & $61.53 \%$ & 2 \\
Brazil & 3 & $17.64 \%$ & 14 & $82.35 \%$ & 0 \\
Egypt & 12 & $42.86 \%$ & 14 & $50.00 \%$ & $2 / 1$ \\
India & 4 & $50.00 \%$ & 0 & $0 \%$ & $1 / 3$ \\
Germany & 3 & $23.07 \%$ & 7 & $53.8 \%$ & $2 / 2$ \\
Australia & 5 & $25.00 \%$ & 13 & $65.00 \%$ & $2 / 1$ \\
\hline
\end{tabular}

Table 3: Demographic approach to McDonald's marketing segmentation

\begin{tabular}{lll}
\hline Type of segmentation & Segmentation criteria & McDonald's target segment \\
\hline Demographic & Age & All age \\
& Gender & Male/Female \\
& Income & Low and Middle \\
& Occupations & Students, Employees \\
\hline
\end{tabular}

It's clear that McDonald's does not keep the same menu for different countries. All of them showed some differences compared to other countries. One of the countries that stand out is India. Due to factors like religious beliefs and local customs, a lot of Indians view cattle as a holy symbol. Thus, beef is not welcome in Indian culture. McDonald's took beef products entirely from the menu not only to ensure its profit but also to respect the local culture in a sense. Another country that stands out in this table is Egypt. McDonald's Egypt provides most burger products among these seven countries. The locals seem to have a split preference on different meat kinds. Thus, McDonald's simply offered Egyptians tons of choices to select from their desire. In addition, the fact that China and India are neighboring countries but having two drastically different menus indicates that geographic approach is highly crucial. Another example in this case is that McDonald's Japan sell TeriTama Burger in springtime and Tsukimi Burger in Autumn. Both of these burgers are for sale in limited time and designed to celebrate cherry blossom season and harvest moon festivals respectively [6]. This illustrates how McDonald's segment different regions based on cultural backgrounds.

Another aspect that fits in the geographic approach is the density of a certain area. Those McDonald's in the urban area have a greater chance of testing new products whereas those in rural areas may have a more conservative menu. This was driven by the fact that there are more people visiting the ones in urban areas. Thus, it's more logical for McDonald's to spend on advertisements and coupons in these urban locations about their products.

\subsection{Demographic Approach}

Table 3 illustrates McDonald's demographic approach including age, gender, life-cycle stage occupation, religious belief, and so on. In terms of age, McDonald's segments them into a variety of different groups. As for the young kid, McDonald's designed a special meal for them which is called "Happy Meal". There are three different setups in the U.S market. Meanwhile, they all consist of little fries and milk which are products that are designed for young kids. Oftentimes, there will be toys included in these meals. Though people in other age groups may don't value them enough, its effect on young kids is huge. As for the teenager group who are mostly students, McDonald has not only priced their products aggressively to retain these group of people who are sensitive about the price, but also provide amenities such as Wi-Fi to attract students [5]. As for the grown-up, McDonald's offers them coffee products which cannot be compared to a conventional coffee shop. These designs clearly target customers who belong to different age groups. As for other segment criteria, McDonald's would create a framework that address all these characteristics.

\subsection{Behavioral Approach}

In terms of Behavioral Approach, it plays a significant role within McDonald's segmentation system. In Table 4, it's clear that McDonald's segmentation builder includes the degree of loyalty to the restaurant and Benefits sought. The research from McDonald's UK indicates that $36 \%$ of consumers eat McDonald's food because of its value. This $36 \%$ of respondents buy McDonald's food because they believe McDonald's products bring them great cost benefits [1]. In 
Table 4: Behavioral approach to McDonald's marketing segmentation

\begin{tabular}{lll}
\hline Type of segmentation & Segmentation criteria & McDonald's target segment \\
\hline Behavioral & Degree of loyalty & "Hard core loyals" / "Switchers" \\
& Benefits sought & Cost benefits, time efficiency \\
\hline
\end{tabular}

Table 5: Psychographic approach to McDonald's marketing segmentation

\begin{tabular}{lll}
\hline Type of segmentation & Segmentation criteria & McDonald's target segment \\
\hline Psychographic & Social class & Lower, working \\
& Lifestyle & NA \\
\hline
\end{tabular}

addition, these consumers feel like McDonald's not only provides cheaper prices for its hamburgers, fries, and drinks compared to other fast-food chains, the food portion is also very ideal compared to their competitors. For instance, 20 pieces of chicken nuggets are only a little bit over six dollars which are a dollar more compared to 10 pieces of chicken nuggets. However, McDonald's realize there are other customers who value time efficiency more than the cost benefits. These groups of people may care less about how much they saved from each McDonald's meal, but care more about having a meal which can provide enough energy calories in a certain amount of time. McDonald's, therefore, comes up with different services to satisfy those customers' needs. While Drive-thru has been implemented by McDonald's since the 1960s, McDonald's developed this McDonald app order feature in 2013. Customers just need to order products they want from their mobile apps in advance. Then, they simply need to drive up to the curb of a McDonald's restaurant and scan a code. McDonald's staff would automatically bring their food outside to their cars. This would save the customer from waiting in the line inside the restaurant and lower the burden on the kitchen during rush hour quite a bit.

Meanwhile, another aspect in the behavioral approach is the degree of loyalty. The distinction is quite obvious. There are those "hardcore loyals" and those "switchers" eat McDonald's occasionally according to Table 4 . In this case, figuring out how to retain its customers became the key. In early 2017, McDonald's launched a reward program in its mobile app [3]. The program would record previous transactions and apply the credit to a future transaction. Apparently, McDonald's competitor Taco Bell had launched a program similar to McDonald's program and received a considerable amount of growth because of its program. Though McDonald's is late in the game, McDonald's reward program would still potentially lock down those "switchers", especially those who are sensitive to a price change.

\subsection{Psychographic Approach}

The psychographic approach can be hard to describe. In Table 5 , it indicates that McDonald's mainly values customers' patterns of work and leisure and their lifestyle through the psychographic approach. For instance, customers who come into an urban location between $12 \mathrm{pm}$ to $6 \mathrm{pm}$ indicates that they are the working class who may simply try to grab lunch or dinner. For those who come in between 6om to 12 am are mostly evening and night shift staff, working in various shops nearby McDonald's stores. Therefore during their breaks and when they finish their job, normally visit McDonald's. The last group between 12 am to $12 \mathrm{pm}$, they are mostly the working class again who has to start their work early. Interestingly, this group has proved to be a constant customer. Another reason that explains why the Psychographic approach could be so hard to describe is how it links to the other approach. For instance, similarities between the behavioral approach and psychographic approach can be drawn when it comes to lifestyle. Customers who have a busy lifestyle would value time efficiency as well. Furthermore, the table under the geographical approach indicates there are countries that have vegetable burgers on their menus. This would indicates there is a certain customer base who potentially live in a vegetarian lifestyle. Thus, certain approaches could not be discussed individually.

\section{DISCUSSION}

The reason that McDonald's has to utilize so many different approaches to build marketing segmentation is due to its enormous scale. To accommodate so many consumers, it may have to come down to each individual region management team to conduct marketing segmentation. In this case, a different approach has its own advantages and disadvantages. As for the geographical approach and demographic approach, their advantage is similar to that of researchers who can get a large amount of data to build up the frame. On the contrary, while geographic regions do not guarantee a homogenous preference which could mislead the research, the demographic approach can be too broad for executives to make decisions. Meanwhile, the other two approaches would offer decisionmakers vivid images to implement policies based on Customers' complex lifestyles and sought. However, they could be sometimes very vague and hard to implement in a lot of cases. Nevertheless, these four approaches seemed to work for McDonald's favor according to Figure 1. From 2014 to 2019, while the total return for both the S\&P 500 and Dow Jones Industrials failed to reach the $200 \$$ mark, the total return for McDonald's was within a hair of the $250 \$$ mark. It is clear that McDonald's five-year total return outruns the market, which exemplifies the marketing segmentation implemented by McDonald's is a success. 


\section{Comparison of Cumulative Five-Year Total Return}

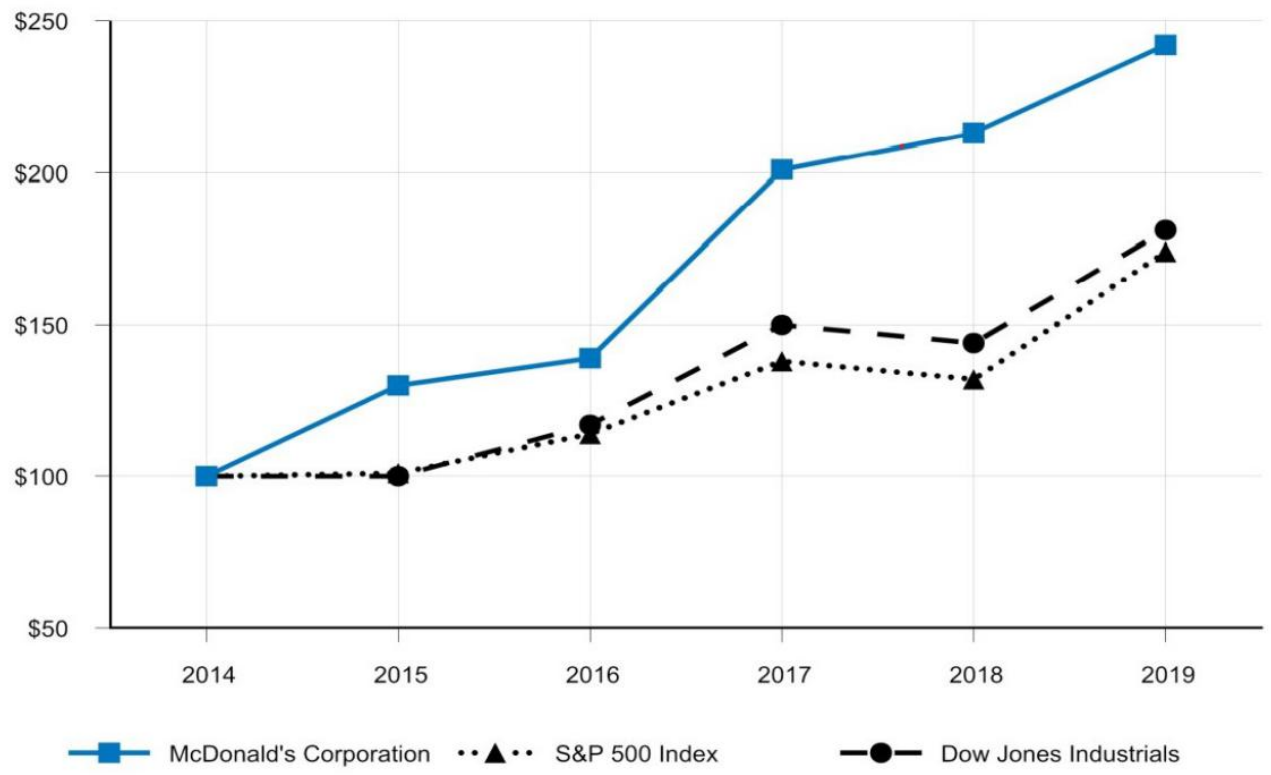

Figure 1: McDonald's Five-Year total return comparison [2]

\section{CONCLUSION}

The four different approaches used by McDonald's to build its marketing segmentation has been proved. Though each of them is only able to contribute a limited amount of impact, utilizing them efficiently could lead to great marketing strategies. Meanwhile, these four marketing segmentation approaches could be used in a variety of other consumer products industry. At the end of the day, getting to know customers better would help any enterprise to develop a better business plan and these approaches here are the key elements that support the research.

\section{ACKNOWLEDGMENTS}

I would like to say thank you to Professor Stephen Coggeshall who helped me develop my business analytic skills as well as offering me guidance on constructing this paper. It has been an honor to work with Professor Coggeshall.

\section{REFERENCES}

[1] Customer retention at McDonalds. UKEssays. ukessays.com, November 2018. Web. 13 August 2020.

[2] McDonald's. 2019 annual report, February 26, 2020. corporate.McDonalds.web. Aug 13, 2020

[3] Samuely, Alex. McDonald's Loyalty Strategy Matures beyond Mobile Coupon Enticement. Retail Dive, 2017, www.retaildive.com/ex/mobilecommercedaily/howmcdonalds-loyalty-strategy-is-maturing-beyond-mobile-coupon-enticement.

[4] McDonald's Menu: Our Full McDonald's Food Menu: McDonald's. www.mcdonalds.com/us/en-us/full menu.html. 2020

[5] The concept of segmentation and its process. 11 2018. UKEssays.https: //www.ukessays.com/essays/marketing/the-concept- of-segmentation-and-itsprocess-marketing-essay.php?vref $=1$.

[6] Keenan, Michael. Geographic Segmentation: What It Is and Why You Need It. ManyChat Blog, 3 Aug. 2020, manychat.com/blog/geographic-segmentation/. 